\title{
Identificação da fração antimicrobiana do extrato da Mimosa tenuiflora
}

\author{
Ivanildo Viana Borges*, Leonardo Sousa Cavalcanti, \\ Acácio Figueirêdo Neto, Jackson Roberto Guedes Da Silva Almeida, \\ Larissa Araújo Rolim, Edigenia Cavalcante Da Cruz Araújo
}

Universidade Federal do Vale do São Francisco, Petrolina, PE, Brasil Autor correspondente, e-mail: ivanildo.borges@univasf.edu.br

\begin{abstract}
Resumo
Na pesquisa de moléculas e compostos antifúngicos com baixa periculosidade, faz-se relevante a ação inespecífica destes, pois há possibilidade de se tornarem inativos devido ao desenvolvimento de resistência. Com o objetivo de aumentar as alternativas para o controle de Curvularia inaequalis e Colletotrichum gloeosporioides, cascas de M. tenuifora foram coletadas e processadas para a obtenção do extrato aquoso, que em seguida foi fracionado através de cromatografia em coluna, cromatografia em camada delgada, e analisado através de cromatografia líquida de alta eficiência (CLAE), para identificação dos compostos ativos. Com as fases obtidas, realizaram-se testes de germinação com C. inaequalis. Na fase "um" foi identificada a presença dos flavonoides catequina e apigenina. Essa fase apresentou atividade de degradação ou inibição da formação da camada de quitina de $C$. inaequalis e as outras fases não mostraram atividade nas concentrações avaliadas. A catequina também apresentou inibição da germinação de C. inaequalis. Quando avaliado o extrato bruto sobre a germinação de C. gloeosporioides, todas as concentrações foram eficientes na inibição da germinação, sendo que a partir de $4 \mathrm{mg} \cdot \mathrm{mL}^{-1}$ a inibição foi de $100 \%$. A fase "um" e a catequina inibiram a germinação de C. inaequalis e o extrato bruto inibiu, de forma semelhante à fase "um", a germinação de C. gloeosporioides.
\end{abstract}

Palavras-chave: Antifúngicos, Compostos ativos, Flavonoides

\section{Identification of the antimicrobial fraction of Mimosa tenuiflora extract}

\begin{abstract}
In the search of molecules and antifungal compounds with low hazard, it is important the compound inespecific action, since there is a possibility of inactivity due to the resistance development. In order to increase the alternatives for the Curvularia inaequalis and Colletotrichum gloeosporioides control, husks of $M$. tenuiflora were collected and processed for obtaining the aqueous extract, which was then fractionated by column chromatography, thin layer chromatography and analysed by high-performance liquid chromatography (HPLC), aiming the identification of active compounds. After obtaining the phases, germination tests were carried out with $C$. inaequalis. The phase "one" showed the presence of flavonoids catechin and apigenin. This phase presented degradation or inhibition of chitin layer formation in $C$. inaequalis and the other phases presented no activity for the evaluated concentrations. Catechin also presented inhibition of $C$. inaequalis germination. For the evaluation of the effect of crude extract on C. gloeosporioides germination, all concentrations were effective in inhibiting germination, and when $4 \mathrm{mg} \cdot \mathrm{mL}^{-1}$ or higher concentrations were used, the inhibition was $100 \%$. The phase "one" and the catechin inhibit the C. inaequalis germination and the crude extract inhibited, similarly to phase "one", the germination of C. gloeosporioides.
\end{abstract}

Keywords: Antifungal agents, Active compounds, Flavonoids. 


\section{Introdução}

Os antimicrobianos são largamente pesquisados tanto na área vegetal quanto animal, com o enfoque em substituir os produtos mais agressivos ao homem e ao ambiente, assim como substituí-los quando se tornam inativos. Uma série de pesquisas apontam alternativas e novas descobertas sobre o comportamento da molécula ou composto ativo e do microrganismo.

Encontra-se na literatura a atividade de moléculas sintéticas que agem eficientemente sobre patógenos que muitas vezes são específicos, atingindo um único alvo celular, desordenando as funções da membrana celular, impedindo a divisão celular, inibindo a síntese de proteínas e ácidos nucleicos e desativando as funções da mitocôndria (Yang et al., 2011). Essa especificidade e direcionamento das moléculas químicas sobre uma organela ou a inibição dos processos vitais da célula pode acelerar o desenvolvimento de resistência dos microrganismos aos antibióticos, pelo desenvolvimento de mutantes, novas cepas, ou pela criação de mecanismos capazes de reconhecer a molécula maléfica e até transportá-la para o meio extracelular (Kretschmer et al., 2009).

O desafio não é apenas encontrar uma molécula eficaz, mas também garantir sua longevidade. Para tanto, é necessário que se utilize mais de um método de controle, principalmente no que se refere aos fatores ecológicos desfavoráveis aos microrganismos, pois o microrganismo necessita de condições especiais para o seu desenvolvimento. Tal associação pode ser fundamental para evitar maiores danos, já que a eliminação desses microrganismos é uma tarefa árdua, considerando a sua adaptabilidade, velocidade de mutação e surgimento de novas cepas, além do desenvolvimento de mecanismos de defesa.

Os extratos de M. tenuiflora e M. hostilis, que segundo a GRIN (2010) são sinônimos, têm demostrado atividade antimicrobiana contra uma série de patógenos (Souza et al., 2008; Borges et al., 2013) além de apresentar atividade antioxidante, cicatrizante, anti-inflamatória (Cruz, 2013) e no tratamento de úlceras (Rivera-Arce et al., 2007). Há muitos relatos sobre a eficiência de extratos vegetais e óleos essenciais no controle de fitopatógenos de interesse em pós-colheita, como pode ser observado nos estudos realizados por Celoto et al. (2011), que ao utilizarem extratos vegetais de Momordica charantia contra Colletotrichum musae, observaram efeito semelhante entre o fungicida tiofanato metílico e o extrato vegetal. Óleos essenciais de alecrimpimenta, alfavaca-cravo, capim santo, cidrão e goiaba apresentaram atividade contra C. gloeosporioides (Sousa et al., 2012).

Este trabalho teve como objetivo identificar a fase e os compostos antifúngicos dos extratos de M. tenuiflora na inibição de Curvularia inaequalis e Colletotrichum gloeosporioides.

\section{Metodologia}

Preparo do extrato

As cascas do caule de M. tenuiflora foram coletadas em uma área de Caatinga no município de Petrolina-PE, no mês de agosto de 2014 (coordenadas: 9019' S, 40³1' W). Os ensaios foram desenvolvidos nos laboratórios de Bioquímica Vegetal, Química Orgânica e Microbiologia na Universidade Federal do Vale do São Francisco (UNIVASF), Campus de Juazeiro; bem como no Laboratório de Bioquímica e na Central de Análise de Fármacos, Medicamentos e Alimentos (CAFMA) no campus da UNIVASF em Petrolina. O material vegetal coletado foi seco ao ar $\left(35-40{ }^{\circ} \mathrm{C}\right)$ e pulverizado em moinho mecânico. Posteriormente, $50 \mathrm{~g}$ do material triturado foram transferidos para um erlenmeyer de $250 \mathrm{~mL}$ e adicionou-se $200 \mathrm{~mL}$ de água. $\mathrm{O}$ material vegetal seco e pulverizado ficou em contato com a solução extratora por 72 horas, em seguida filtrou-se o extrato obtido, secando-o ao ar até a obtenção do extrato sólido. Para o ajuste da concentração dos extratos foi utilizada a equação linear $y=0,00111+0,02832 x ; R^{2}=0,99$ obtida através do programa computacional Origin $^{\circledR} 7.0$, onde, "y" representa a absorbância em 550 nm e " $x$ " a concentração em mg. $\mathrm{mL}^{-1}$ segundo Borges et al. (2013).

Processo de obtenção das fases do extrato bruto de jurema preta

Nos processos de separação das fases do extrato bruto por cromatografia em coluna 
(CC) foi utilizada como fase estacionária Sephadex ${ }^{\circledR}$ LH 20 e metanol como fase móvel. Nas análises utilizando-se cromatografia em camada delgada (CCD) foram utilizadas placas pré-preparadas 20×20 de sílica gel 60 (0,20 mm de sílica gel com indicador de fluorescência UV $254 \mathrm{~nm}$ ). As placas de CCD foram reveladas sob luz UV em 254 e 365 nm. As frações obtidas em CC foram analisadas em CCD utilizando-se metanol como elvente, e logo após essa etapa foram reunidas as frações obtendo-se nove fases.

Revelação de flavonoides

As nove fases reunidas foram analisadas em CCD e eluídas em fase móvel apropriada. Para revelação das placas foram utilizados os reagentes NR + PEG (NR: ácido difenilbórico 2-amino-etil-éster; PEG: polietileno glicol), as quais foram observadas sob luz ultravioleta em $365 \mathrm{~nm}$ no escuro.

\section{Análise da fração ativa por CLAE-DAD}

Para determinação quali-quantitativa de metabólitos secundários da fração ativa obtida do extrato bruto de M. tenuiflora foi utilizado um cromatógrafo líquido de alta eficiência (CLAE) ShimadzU ${ }^{\circledR}$ LC-20 com detector de arranjo de diodos (DAD), equipado com um sistema quaternário de bombas modelo LC - 20ADVP, degaseificador modelo DGU - 20A, detector PDA modelo SPD - 20AVP, forno modelo CTO - 20ASVP, injetor automático modelo SIL - 20ADVP e controlador modelo SCL - 20AVP, sendo os dados tratados através do software Shimadzu ${ }^{\circledR}$ LC solution 1.0 (Japão).

A fase móvel utilizada foi composta de dois solventes: solvente A - $0.1 \%$ de ácido fórmico diluído em água ultrapura (grau CLAE) e solvente B - $100 \%$ de acetonitrila com fluxo de $1 \mathrm{~mL} \cdot \mathrm{min}^{-1}$, em gradiente.

$\mathrm{Na}$ determinação quali-quantitativa da apigenina e catequina utilizou-se os seguintes gradientes para o solvente A: 100; 60; 60; 100\% e para B: 0; 40; 40; 0\% nos intervalos de 0; $50 ; 60$ e 90 minutos, respectivamente.

A fase estacionária foi uma coluna TSK-GEL Super-ODS (Supelco ${ }^{\circledR}$ ) mantida a 37 ${ }^{\circ} \mathrm{C}$. O volume das amostras injetado foi de $20 \mu \mathrm{L}$, sendo monitoradas em 270 e $340 \mathrm{~nm}$.
Para determinação quantitativa dos padrões analíticos apigenina e catequina (adquiridos da Sigma-Aldrich ${ }^{\circledR}$, grau analítico com pureza superior a 99\%) nas amostras foram obtidas curvas analíticas nas concentrações de 50, 100, 125, 150 e $200 \mu \mathrm{g} \cdot \mathrm{mL}^{-1}$, sendo a amostra analisada a $500 \mu \mathrm{g} \cdot \mathrm{mL}^{-1}$ em triplicata.

Teste qualitativo antimicrobiano das fases do extrato sobre Curvularia inaequalis

Para avaliar a atividade antifúngica das fases do extrato de M. tenuiflora, utilizou-se um isolado de Curvularia inaequalis, obtido de uma coleção da Universidade Estadual de Feira de Santana, que foi cultivada em batata dextrose ágar (BDA) e incubada por sete dias em BOD (Demanda Bioquímica de Oxigênio) a $25^{\circ} \mathrm{C}$ e fotoperíodo de 12 horas.

Ao atingir sete dias de incubação, foram adicionados $10 \mathrm{~mL}$ de água destilada e esterilizada (ADE) em cada placa de Petri. O micélio foi raspado com auxílio de uma escova para liberação dos conídios e filtrado em gaze estéril. A concentração da suspensão dos conídios foi determinada em câmara de Neubaver e expresso em conídios. $\mathrm{mL}^{-1}$.

Uma suspensão de $40 \mu \mathrm{L}$ a $10^{5}$ conídios. $\mathrm{mL}^{-1}$ foi adicionada às cavidades da placa de ELISA contendo $40 \mu \mathrm{L}$ das fases do extrato bruto (EB), previamente esterilizado em filtro milipore $(0,2 \mu \mathrm{m})$, nas seguintes concentrações de 3,125; 6,25; 9,375 e 12,5 mg. $\mathrm{mL}^{-1}$, em três repetições.

As placas de ELISA foram incubadas em BOD durante 20 horas sob luz constante e temperatura de $25^{\circ} \mathrm{C}$. Considerou-se germinados os conídios que apresentavam tubo germinativo igual ou maior que o esporo, conforme Itako et al. (2009).

Essa análise foi apenas qualitativa e teve como objetivo definir a fase antifúngica do extrato bruto para ser identificada em CLAE.

Avaliação dos extratos brutos de M. tenuiflora sobre a germinação de Colletotrichum gloeosporioides

Para o teste de atividade antimicrobiana dos extratos brutos utilizou-se um isolado de C. gloeosporioides, obtidos de frutos com sintomas característicos da doença, coletados em uma 
propriedade particular no município de Petrolina$P E$, que depois de purificado foi cultivado em BDA e incubada por sete dias em BOD a $25^{\circ} \mathrm{C}$ e fotoperíodo de 12 horas.

Ao atingir sete dias de incubação, foram adicionados $10 \mathrm{~mL}$ de água destilada e esterilizada (ADE) em cada placa de Petri. $O$ micélio foi raspado com auxílio de uma escova para liberação dos conídios e filtrado em gaze. A concentração da suspensão dos conídios foi determinada em câmara de Neubaver e expresso em conídios. $\mathrm{mL}^{-1}$.

Uma suspensão de $40 \mu \mathrm{L}$ a $10^{5}$ conídios. $\mathrm{mL}^{-1}$ foi adicionada às cavidades da placa de ELISA contendo $40 \mu \mathrm{L}$ do extrato bruto (EB), nas concentrações de 0,$0 ; 2,0 ; 4,0 ; 6,0 ; 8,0$ e 10,0 $\mathrm{mg} \cdot \mathrm{mL}^{-1}$, sendo cinco repetições.

As placas de ELISA foram incubadas em BOD durante 20 horas sob luz constante e temperatura de $25^{\circ} \mathrm{C}$. Considerou-se germinados os esporos que apresentavam tubo germinativo igual ou maior que o esporo, seguindo instruções de ltako et al. (2009).

Para avaliação estatística dos dados foi utilizada regressão na análise de variância, utilizando se o programa computacional ASSISTAT.

Avaliação antimicrobiana da catequina sobre conídios de Curvularia inaequalis

Foram adotados os mesmos procedimentos para cultivo e concentração dos conídios de $C$. inaequalis, sendo o teste também realizado em placas de ELISA, assim como foi citado para o teste antimicrobiano com as fases do extrato. Foram utilizadas as seguintes concentrações de catequina: 0,$75 ; 1,5$ e 3,0 $\mathrm{mg} \cdot \mathrm{mL}^{-1}$.

O delineamento experimental foi inteiramente ao acaso com seis repetições e as médias dos tratamentos foram comparadas pelo Teste de Tukey a $5 \%$ de probabilidade utilizandose o programa computacional ASSISTAT.

\section{Resultados e Discussão}

A partir da análise cromatográfica da fase "um", preliminarmente identificado através da fluorescência desses compostos sob lUz UV em $365 \mathrm{~nm}$ como pertencente ao grupo dos flavonoides, foi possível identificar os dois padrões analíticos utilizados por meio da semelhança entre tempos de retenção e espectro de absorção no ultravioleta, bem como quantificar a catequina em $19 \mathrm{~min}\left(125,33 \pm 1,51 \mu \mathrm{g} \cdot \mathrm{mL}^{-1}\right)$ e a apigenina em $48 \mathrm{~min}\left(1,72 \pm 0,58 \mu \mathrm{g} \cdot \mathrm{mL}^{-1}\right)$ conforme pode ser observado na Figura 1.

Flavonoides obtidos das partes aéreas de M. tenuiflora, pertencentes às classes flavona e flavanona foram identificados por Cruz (2013) dando suporte ao presente estudo que constatou a presença da apigenina, uma flavona, e da catequina, um flavonol. Provavelmente a quantidade de catequina identificada nessa fração esteja relacionada à sua extração com água, pois se trata de um composto solúvel em água. Na análise fitoquímica dos extratos brutos de $M$. tenuiflora foi possível identificar a presença de catequinas, flavonas, taninos, antocianinas, antocianidinas, xantonas, esteroides, triterpenoides, saponinas e alcaloides (Bezerra et al., 2011).

A catequina apresenta atividade antiviral, inibindo a polimerase viral do HIV, hepatoprotetora, antimicrobiana, inativa toxinas, inibe a síntese de ácidos graxos, tem atividade sobre a lipogênese em células do câncer da próstata, paralisa e causa morte celular (Kumar \& Pandey, 2013). A catequina apresenta atividade antibacteriana contra Escherichia coli, Listeria innocua e Staphylococcus aureus (Rawdkuen et al., 2012) e para dois isolados de Helicobacter pylori (Díaz-Gómez et al., 2013). Flavonoides isolados de Mimosa diplotricha apresentaram atividade antiproliferativa contra linhagens de células tumorais e de cancro originados de humanos (Lin et al., 2011).

A catequina também foi confirmada por espectrometria de massas em M. caesalpinifolia, sendo os extratos polares (água e etanol) os mais eficientes na extração. Os extratos originados mostraram inibição da proliferação de células tumorais quando comparados com o controle positivo doxorubicina. Os polifenóis encontrados nas espécies de Mimosa estão associados a propriedades biológicas e farmacológicas (Monção et al., 2015).

A atividade terapêutica dos extratos de folhas, cascas e partes aéreas de $M$. 
A

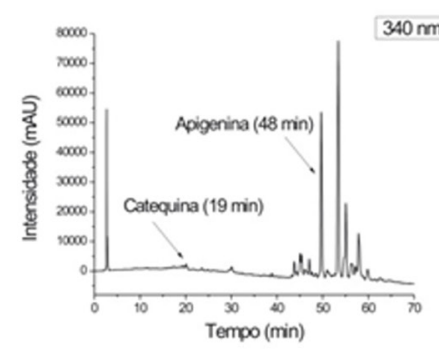

$\mathrm{D}$

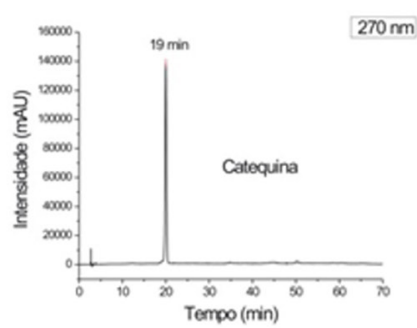

B

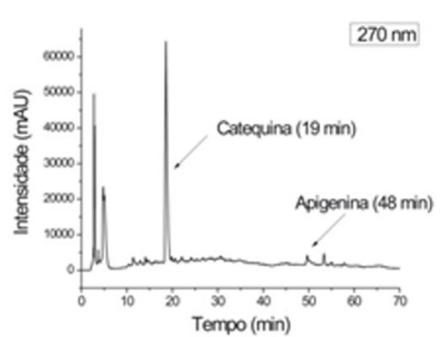

$\mathrm{E}$

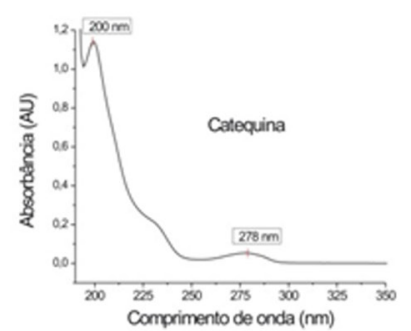

C

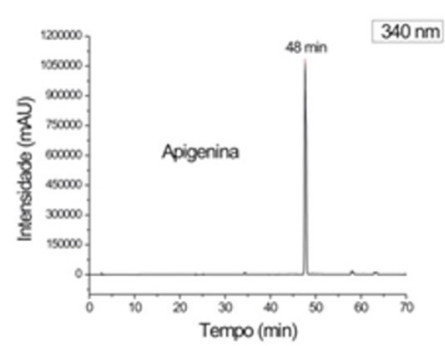

$\mathrm{F}$

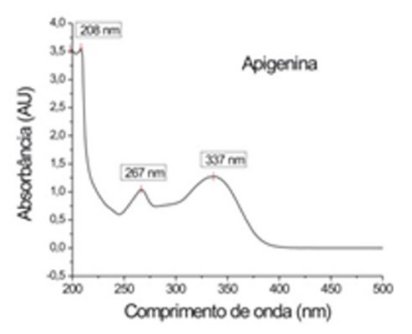

Figura 1. Cromatogramas obtidos da fase "um" (concentrado com tonalidade amarelado) fracionado do extrato bruto aquoso da casca de M. tenuiflora e espectros de absorção em ultravioleta dos padrões analíticos. (A) Absorção da fase em 340 nm; (B) Absorção da fase em 270 nm; (C) Absorção do padrão apigenina em 340 nm; (D) Absorção do padrão catequina em 270 nm; (E) Absorção do padrão catequina em $200 \mathrm{~nm}$ e (F) Absorção do padrão apigenina em $200 \mathrm{~nm}$

hostilis foi comprovada por Cruz (2013). Seus estudos revelaram a inibição de $26 \%$ da acetilcolinesterase (AChE), enzima que acelera a doença de Alzheimer, utilizando flavonoides extraídos das folhas, revela ainda atividade antiinflamatória, antinociceptiva, antioxidante e antimicrobiana das cascas.

O outro flavonoide quantificado em menor quantidade na fase também apresenta atividade antimicrobiana, como pode ser confirmado por Nayaka et al. (2014) ao afirmar que a apigenina extraída de Portulaca oleracea mostrou atividade antimicrobiana contra Pseudomonas aeruginosa, Salmonella typhimurium, Proteus mirabilis, Klebsiella pneumoniae e Enterobacter aerogenes sobre concentrações menores que $4 \mathrm{mg} \cdot \mathrm{mL}^{-1}$. A apigenina também foi capaz de induzir a morte celular de células cancerosas da bexiga, in vitro, apresentando atividade antitumoral, sendo um potencial quimiopreventivo do câncer da bexiga (Zhu et al., 2013). Apesar de ser um quimioprotetivo potencial na prevenção de câncer, inclusive leucemia, a sua ingestão pode reduzir a sensibilidade à quimioterapia, dependendo do tipo de célula, mas ainda assim, sua ingestão é indicada no tratamento de câncer (Sousa et al., 2010). Atividade da apigenina, semelhantes aos citados, também foram observados para o tratamento de câncer de mama (Cao et al., 2013).

Avaliação qualitativa da atividade das fases e do extrato bruto de $M$. tenuiflora sobre a germinação de Curvularia inaequalis

No teste qualitativo, para descobrir a fase do extrato bruto com atividade antifúngica, houve destaque da fase "um", identificada como sendo um composto do grupo dos flavonoides, que inibiu totalmente a germinação dos conídios de $C$. inaequalis em todas as concentrações avaliadas, agindo sobre a parede celular, degradando-a e/ou impedindo a sua síntese e, em consequência, aumentado a vulnerabilidade dos protoplastos, que sem a proteção da parede celular ficam mais expostas as condições adversas do ambiente, aumentando a permeabilidade da membrana com a perda da seletividade, levando-as ao estouro, lise celular (Figura 2B). Os fungicidas, além de agir sobre a permeabilidade da membrana inibindo a biossíntese de esterol nas células fúngicas, podem interferir na síntese de aminoácidos e proteínas; na respiração, desordenando as funções da mitocôndria na síntese de ácidos nucleicos e na divisão celular (Yang et al., 2011).

Nas concentrações de 9,37 e 12,5 mg.mL-1 foram observadas poucas 


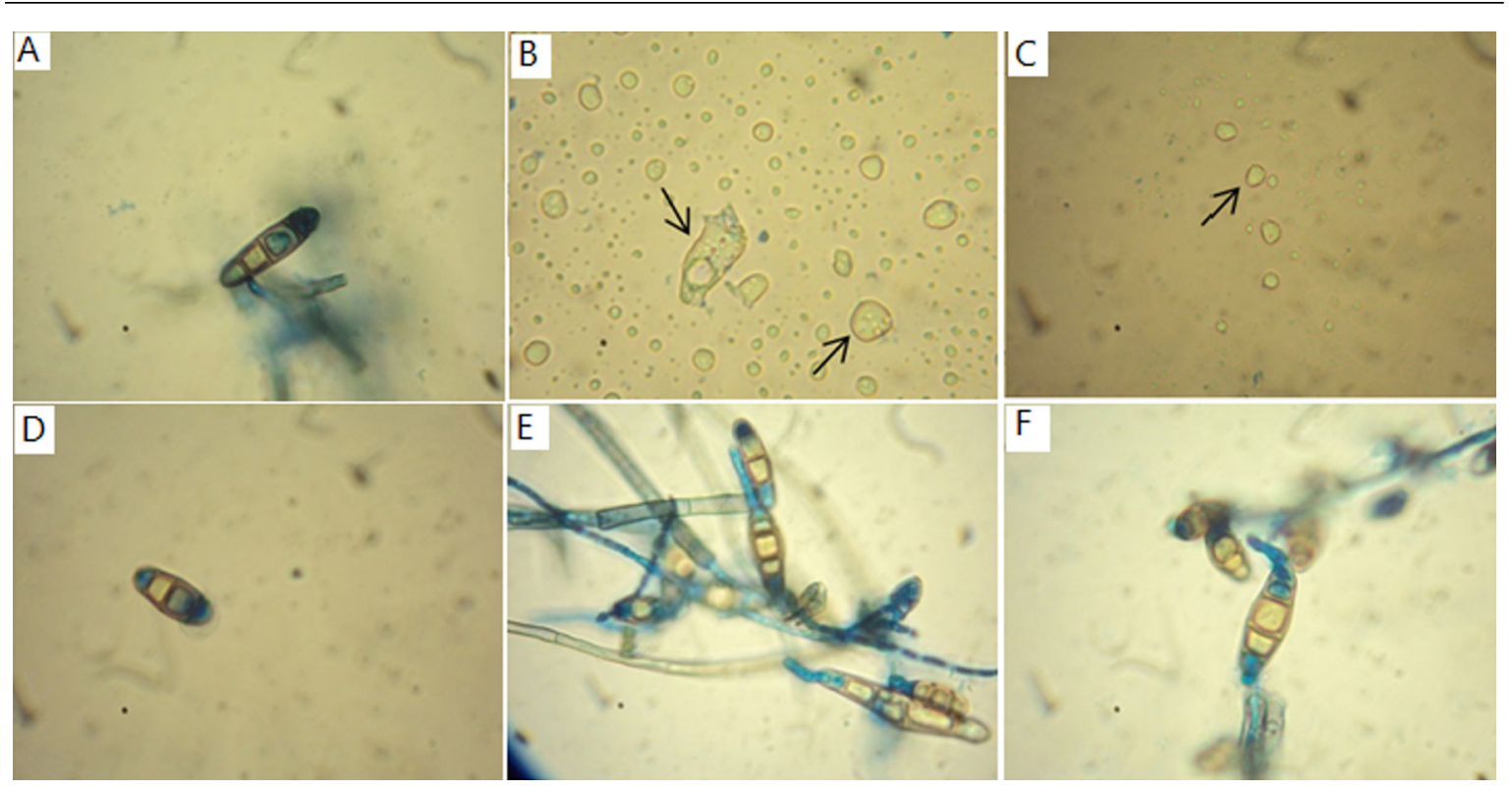

Figura 2. Atividade das fases do extrato bruto de M. tenuiflora sobre conídios de Curvularia inaequalis. (A) Conídio sem nenhuma alteração, germinando, testemunha; (B) protoplastos sem a camada de quitina, efeito da fase "01" a 6,25 mg. $\mathrm{mL}^{-1}$, indicado pela seta preta, a esquerda lise celular; (C) poucos protoplastos sem a camada de quitina, efeito da fase "01" a 9,37 mg.mL -1, indicado pela seta preta;(D) conídio sem alteração, efeito da fase 5+6; (E) conídios germinando, efeito da fase 7+8 e (F) conídios germinando, efeito da fase 9 . Figuras capturadas em microscópio óptico na objetiva de 40 e auxílio de câmara digital 12 megapixels com aumento de 6x (vezes).

células. Provavelmente, com o aumento da concentração dos flavonoides, há maior lise das células, e portanto, com o aumento da concentração, houve redução do número de células observadas (Figura 2C). A fase 5+6 não mostrou alteração expressiva no conídio (Figura 2D). A fase 7+8 e 9 apresentaram algum estímulo à germinação (Figura 2E). Entretanto, a atividade dessas fases necessitam ser melhor avaliada e quantificada. Resultados semelhantes foram observados por Borges et al. (2013) ao avaliar extratos brutos de Mimosa tenuiflora no controle de Alternaria cucumerina. Segundo esses autores, o extrato induz a exposição dos protoplastos ao meio contendo os extratos, que não conseguem restabelecer a parede celular. Esses autores também observaram variações na atividade dependo da concentração, método de extração e solução extratora que podem inibir ou estimular a germinação. A atividade dos extratos foi atribuída a uma provável atividade dos taninos, que complexam proteínas e íons metálicos, inibem enzimas e afetam a utilização de vitaminas, proporcionando efeito antimicrobiano e antifúngico (Monteiro et al., 2005). Entretanto, o fracionamento dos compostos do extrato bruto, realizado neste trabalho através de cromatografia em coluna seguida pela análise da fase ativa por CLAE, revelou que os compostos da fase, com atividade antimicrobiana, pertencem ao grupo dos flavonoides, principalmente da catequina encontrado em maior concentração e apigenina, em menor concentração na fração analisada. Nesta separação foram obtidas seis fases reunidas, fase 1, 5, 6, 7, 8, 9 .

O mecanismo de ação dos flavonoides se dá pela ampla capacidade que os mesmos possuem de inibir a germinação de fitopatógenos e ainda combatem infecções fúngicas no homem (Salas et al., 2011). Esses compostos formam complexos com as proteínas das paredes dos fungos e são capazes de romper suas paredes (Arif et al., 2011).

A ação dos flavonoides observado por Salas et al. (2011) e Arif et al. (2011) é similar à observada no presente trabalho, confirmando que há grande probabilidade da atividade desses extratos estarem relacionado aos flavonoides presentes no extrato bruto, porém, não pode-se descartar que os outros compostos fenólicos existentes no extrato tenham alguma atividade.

Avaliação quantitativa da atividade da catequina sobre a germinação de conídios de 
Curvularia inaequalis

Levando-se em consideração que a substância em maior quantidade detectada na fase ativa do extrato bruto, pelos padrões analíticos, foi a catequina, realizou-se um teste com a catequina pura para confirmar se a atividade antimicrobiana do extrato tem relação com o referido flavonoide. A catequina inibiu significativamente a germinação dos conídios de Curvularia inaequalis (Figura 3), em todas as concentrações avaliadas, não havendo diferença significativa entre as concentrações, mas o seu mecanismo difere dos apresentados pela fase ativa do extrato ao se comparar as observações realizadas no microscópio óptico. Quando se observou as estruturas do fungo sobre ação da fase do extrato não se observou conídios de C. inaequalis, apenas os protoplastos em todas as concentrações avaliadas, em contrapartida quando as observações foram realizadas sob efeito da catequina, os conídios germinados e não germinados apresentaram-se sem nenhuma alteração.

Talvez, a liberação dos protoplastos seja uma ação da apigenina, da junção desses

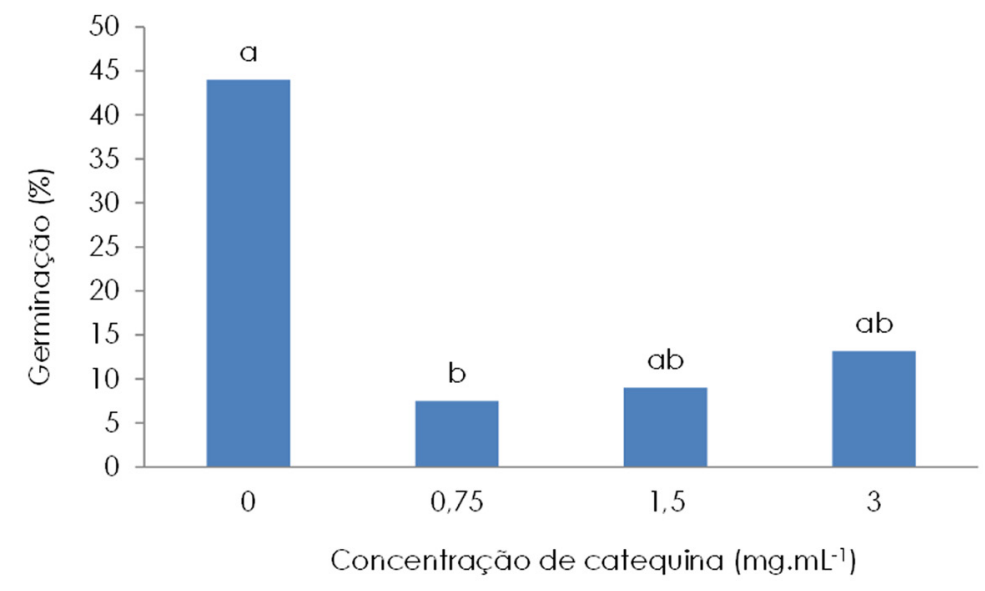

Figura 3. Germinação dos conídios de C. inaequalis sob catequina. As médias seguidas pela mesma letra não diferem estatisticamente entre si pelo teste de Tukey ao nível de $5 \%$ de probabilidade

dois flavonoides ou até de outra substância não detectada por falta de padrões compatíveis. No presente estudo não foi possível avaliar a ação isolada da apigenina sobre a germinação de conídios de C. inaequalis. Nos estudos realizados por Liu et al. (2013), a concentração mínima inibitória da apigenina foi 1,95 $\mu \mathrm{g} \cdot \mathrm{mL}^{-1}$ para $S$. aureus e 3,91 $\mu \mathrm{g} \cdot \mathrm{mL}^{-1}$ para Bacillus subtilis, E. coli, e Pseudomonas aeruginosa.

Foi observada uma maior atividade antimicrobiana nas sementes da P. oleraceae, rica em apigenina. Enquanto a concentração inibitória mínima (CIM) para extrato etanólico das folhas foi de 200 ppm para sementes a CIM foi reduzida para 100 ppm (Mousavi, Bagheri \& Saeidi, 2015). Das 11 (onze) espécies vegetais estudados por Andarwulan, et al. (2010), dentre essas a $P$. oleraceae, os flavonoides que aparecem em maior quantidade são quercetina e kaempferol, responsáveis por $60 \%$ ou mais dos flavonoides, enquanto miricetina,
Iuteolina e apigenina são os menos abundantes. Nesse estudo, foi quantificado em P. oleraceae aproximadamente $97 \%$ de quercetina e $3 \%$ de apigenina. Mesmo apresentando proporções muito pequenas a atividade da $P$. oleraceae tem sido atribuída à apigenina. Essa flavona também pode estar agindo em sinergismo com a catequina e atribuindo ação antimicrobiana aos extratos de $M$. tenuiflora.

Pela metodologia utilizada foi possível separar $25 \mathrm{mg}$ da fase com atividade antimicrobiana de $1000 \mathrm{mg}$ do extrato bruto, ou seja, 2,5\%, sendo que desse percentual, considerando apenas esses compostos, aproximadamente 1,4\% é de apigenina e 98,6\% de catequina.

Atividade dos extratos brutos de M. tenuiflora sobre germinação de conídios de Colletotrichum gloeosporioides

$\mathrm{Na}$ avaliação quantitativa da 
germinação de C. gloeosporioides o extrato bruto aquoso mostrou-se eficiente na inibição da germinação dos conídios em todas as concentrações avaliadas (Figura 4).

O efeito tóxico do extrato foi suficiente para inibir $100 \%$ da germinação dos conídios

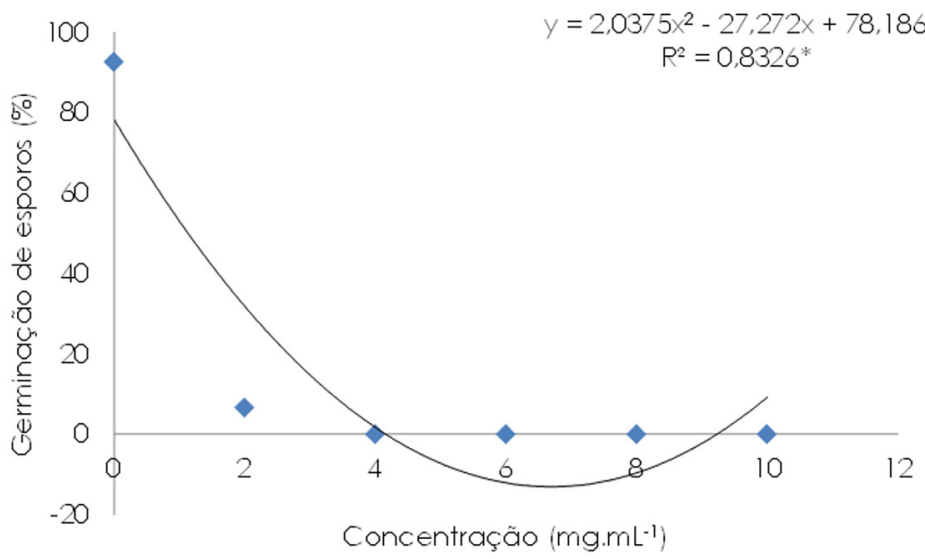

Figura 4. Germinação dos conídios de C. gloeosporioides sob extratos brutos de M. tenuiflora, ajustado pela equação de regressão. " Modelos matemáticos de regressão significativos a $5 \%$ de probabilidade pelo Teste $\mathrm{F}$

de C. gloeosporioides a partir de $4 \mathrm{mg} \cdot \mathrm{mL}^{-1}$. A sua atividade está relacionada à atividade dos flavonoides presente no extrato bruto, dentre eles a catequina e apigenina. Os extratos brutos da casca de $M$. tenuiflora também foram eficientes na inibição de Staphylococcus aureus (Bezerra et al., 2009) e Candida spp. (Pereira et al., 2009), isoladas de leite de vaca com histórico de mastite, em várias concentrações, sendo que para o $S$. aureus a eficiência dos extratos foi superior aos antibióticos penicilina e azitromicina (Bezerra et al., 2009). Estudos realizados por Higino et al. (2015) com extratos de Mimosa arenosa também confirmam o potencial antimicrobiano das espécies do gênero Mimosa. Nesse estudo os autores confirmam a atividade antimicrobiana dos extratos frente a $S$. aureus. Inibição de $100 \%$ da germinação de C. gloeosporioides foi observado por Sousa et al. (2012) ao avaliar óleos essenciais de alecrim-pimenta, alfavacacravo, capim santo, cidrão e goiaba. Celoto et al. (2011) também comprovaram a eficiência dos extratos aquosos de Momordica charantia que inibiram $100 \%$ da germinação e $71 \%$ (meio sólido) e $86 \%$ (meio líquido) do crescimento micelial de Colletotrichum musae. Para germinação o extrato a $50 \%$ não apresentou diferença significativa com o fungicida tiofanato metílico na concentração de $1000 \mu \mathrm{g} \cdot \mathrm{mL}^{-1}$;

Efeito similar ao da fase "um" do extrato bruto identificado como sendo flavonoide, foi observado para C. gloeosporioides, quando tratado com extrato bruto de $M$. tenuiflora a $10 \mathrm{mg} \cdot \mathrm{mL}^{-1}$ (Figura 5B), assegurando que a ação fungitóxica/fungistática do extrato tem correlação com os flavonoides detectados em CLAE da fase "um". Nesse mesmo experimento observou-se que o extrato inibe a germinação e causa deformação nos conídios de C. gloeosporioides em todas as concentrações avaliadas (Figura 5C). A deformação no conídio pode impedir ou dificultar os processos de infecção do patógeno, que necessita emitir estruturas especializadas, como o haustório, durante a infecção do tecido vegetal sadio.

Além de se pesquisar alternativas aos produtos químicos utilizados no controle de patógenos deve, também, haver preocupação com o seu mecanismo de ação perante 0 patógeno em questão, pois os microrganismos são capazes de desenvolver várias rotas de resistência para as moléculas químicas, sejam elas, qualitativas, baseadas em mutações, ou quantitativas, que pode ser através de efluxo de moléculas para o meio extracelular e até a seletividade na membrana impedindo a entrada de moléculas indesejáveis (Deising, Reimann \& Pascholati, 2008).

A resistência a múltiplas drogas (MDR), desenvolvida por microrganismos, caracterizada pelo aumento do efluxo de drogas do meio intracelular para o extracelular foi observada 
por Kretschmer et al. (2009) para Botrytis cinerea a qual apresentou redução da sensibilidade a fungicidas. Nesse estudo foram identificadas três cepas diferentes, caracterizadas como MDR1, MDR2 e MDR3. A MDR1 apresentou níveis de resistência a fludioxonil, ciprodiniloe tolnaftato,
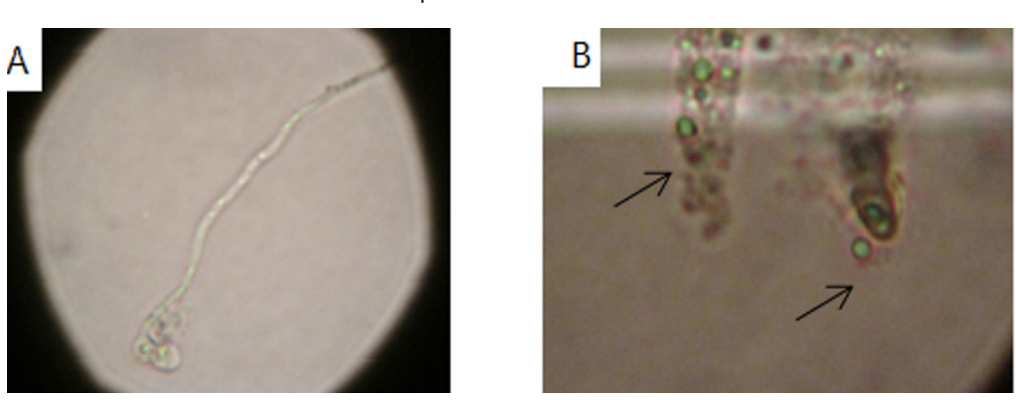

M. tenuiflora pode ser atribuída à presença de flavonoides no extrato presentes na fase 1. O extrato bruto inibiu totalmente a germinação de Colletotrichum gloeosporioides a partir de $4 \mathrm{mg} \cdot \mathrm{mL}^{-1}$ e a fase contendo flavonoides inibiu totalmente a germinação de Curvularia inaequalis em todas as concentrações avaliadas.

\section{Agradecimentos}

Os autores gostariam de agradecer a Célia Virgínia Alves de Souza, pela leitura e revisão ortográfica do manuscrito.

\section{Referências}

Andarwulan, N., Batari, R., Sandrasari, D.A., Bolling, B., Wijaya, H. 2010. Flavonoid content and antioxidant activity of vegetables from Indonesia. Food Chemistry 121:1231-1235.

Arif, T., Mandal, T.K., Dabur, R. 2011. Natural products: Anti - fungal agents derived from plants, Research Signpost 81:283 - 311.

Bezerra, D.A.C., Pereira, A.V., Lôbo, K.M.S., Rodrigues., O.G., Athayde, A.C.R., Mota, R.A., Medeiros, E.S., Rodrigues, S.C. 2009. Atividade biológica da jurema-preta (Mimosa tenuiflora (Wild) Poir.) sobre Staphylococcus aureus isolado de casos de mastite bovina, Revista Brasileira de Farmacognosia 19:814-817.

Bezerra, D.A.C., Rodrigues, F.F.G., Costa, J.G.M., Pereira, A.V., Sousa., E.O., Rodrigues., O.G. 2011. Abordagem fitoquímica, composição bromatológica e atividade antibacteriana de Mimosa tenviflora (Wild) Poiret e Piptadenia stipulacea (Benth) Ducke. Acta Scientiarum 33:99 - 106.

Borges, I.V., Peixoto, A.R., Cavalcanti, L.S., Lima, M.A.G., Silva, M.S. 2013. Extratos de jurema

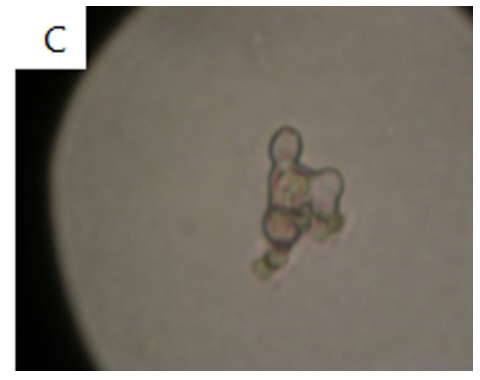

enquanto o MDR2 a fenexamida, tolnaftate, cycloheximide e ciprodinilo e o MDR3 a maioria dos fungicidas testados.

\section{Conclusão}

A atividade antifúngica do extrato de

preta no controle de mancha-de-alternaria em melancia. Revista Caatinga 26:36 - 45.

Cao, X., Liu, B., Cao, W. , Zhang, W. Zhang, F., Zhao, H., Meng, R., Zhang, L., Niu, R., Hao, X., Zhang, B. 2013. Autophagy inhibition enhances apigenininduced apoptosis in human breast cancer cells. Chinese Journal of Cancer Research 25:212-222.

Celoto, M.I.B., Papa, M.F.S., Sacramento, L.V.S., Celoto, F.J. 2011. Atividade antifúngica de extratos de Momordica charantia L. sobre Colletotrichum musae. Revista Brasileira de Plantas Medicinais. 13:337-341.

Cruz, M.P. 2013. Isolamento e identificação de compostos bioativos de mimosa hostilis Benth. $205 \mathrm{f}$. (Tese de doutorado)- Universidade Federal da Bahia, Salvador, Brasil.

Deising, H.B., Reimann, S.R., Pascholati, S.F. 2008. Mechanisms and significance of fungicide resistance. Brazilian Journal of Microbiology 39:286-295.

Díaz-Gómez, R., López-Solís, R., ObrequeSlier, E., Toledo-Araya, H. 2013. Comparative antibacterial effect of gallic acid and catechin against Helicobacter pylori. Food Science and Technology 54:331 - 335 .

GRIN. Germplasm Resources Information Network. 2010. http://www.ars-grin.gov/npgs/ aboutgrin.html/<Acesso em 12 nov. 2015>

Hanumantappa, B.N., Ramesh, L. L., Madire, K. U., Asha, T. 2014. Antibacterial Attributes of Apigenin, Isolated from Portulaca oleracea L. International Journal of Bacteriology 2014:1-8.

Higino, S.S.S., Pereira, A.V., Azevêdo, T.K.B., Santana, G.M., Paula, A.F.R., Trevisan, L.F.A., Azevedo, S.S., Pereira, M.S.V. 2015. Avaliação da atividade antimicrobiana de taninos isolados da jurema vermelha (Mimosa arenosa (Willd Poir) sobre Staphylococcus aureus de origem bovina. 
Agropecuária Técnica 36:115-120.

Itako, A.T., Schwan-Estrada, K.R.F., Stangarlin, J.R., Tolentino Júnior, J.B., Cruz, M.E.S. 2009. Controle de cladosporium fulvum em tomateiro por extratos de plantas medicinais. Arquivos do Instituto Biológico 76:75-83.

Kretschmer, M., Leroch, M., Mosbach, A., Walker, A., Fillinger, S., Mernke, D., Schoonbeek, H., Pradier, J., Leroux, P., Waard, M.A., Hahn, M. 2009. Fungicide-Driven Evolution and Molecular Basis of Multidrug Resistance in Field Populations of the Grey Mould Fungus Botrytis cinerea. PLoS Pathogens 5:1-13.

Kumar, S., Pandey, A.K. 2013. Chemistry and Biological Activities of Flavonoids: An Overview. The Scientific World Journal 2013:1-16.

Liu, R., Zhang, H., Yuan, M., Zhou, J., Tu, Q., Liu, J., Wang, J. 2013. Synthesis and Biological Evaluation of Apigenin Derivatives as Antibacterial and Antiproliferative Agents. Molecules 18:1149611511.

Monção, N.B., Araújo, BQ., Silva, J.do N., Lima, D.J., Ferreira, P.M., Airoldi, F.P., Pessoa, C., Citó, A.M. 2015. Assessing Chemical Constituents of Mimosa caesalpiniifolia Stem Bark: Possible Bioactive Components Accountable for the Cytotoxic Effect of M. caesalpiniifolia on Human Tumour Cell Lines. Molecules 20:4204-4224.

Monteiro, J.M. Albuquerque, U.P de. Araújo, E de L. 2005. Taninos uma abordagem da química à ecologia. Química Nova 28:892-896, 2005.

Mousavi, S.M., Bagheri, G., Saeidi, S. 2015. Antibacterial Activities of the Hydroalcoholic Extract of Portulaca oleracea Leaves and Seeds in Sistan Region, Southeastern Iran. International Journal of Infection 2:1- 4.

Nayaka, H. B., Londonkar, R. L., Umesh, M. K., Tukappa, A. 2014. Antibacterial Attributes of Apigenin, Isolated from Portulaca oleracea L. International Journal of Bacteriology 2014:1- 8.

Pereira, A.V., Rodrigues., O.G., Lôbo, K.M.S., Bezerra, D.A.C., Mota, R.A., Coutinho, L.C.A., Silva, L.B.G., Athayde, A.C.R. 2009. Atividade anti-fúngica do neem e jurema-preta sobre cepas de Candida spp isolados de vacas com mastite subclínica no Estado de Pernambuco. Revista Brasileira de Farmacognosia 19:818-822.

Rawdkuen, S., Suthiluk, P., Kamhangwong, D., Benjakul, S. 2012. Antimicrobial activity of some potential active compounds against food spoilage microorganisms. African Journal of Biotechnology 11:13914-13921.

Rivera-arce, E., Gattuso, M., Alvarado, R., Zárate, E., Agüero, J., Feria, I., Lozoya, X. 2007.
Pharmacognostical studies of the plant drug Mimosae tenuiflorae cortex. J Ethnopharmacol 113: 400-408.

Salas, P.M., Céliz, G., Geronazzo, H., Daz, M., Resnik, S.L. 2011. Antifungal activity and enzymatically - modified flavonoids isolated from citrus species. Food Chemistry 124:1411-1415.

Sousa, R.M.S; Serra, I.M.R.S; Melo, T.A. 2012. Efeito de óleos essenciais como alternativa no controle de Colletotrichum gloeosporioides, em pimenta. Summa Phytopathol 38:42-47.

Sousa, R.R.R., Fuhler, G.M., Blom, M., Ferreira, C.V., Aoyama, H., Peppelenbosch, M.P. 2010. Cytotoxicity of apigenin on leukemia cell lines: implications for prevention and therapy. Cell Death and Disease 1:1-12.

Souza, R. S. O. de, Albuquerque, U. P. de, Monteiro, J. M., Amorim, E. L. C. de. 2008. Jurema-Preta (Mimosa tenuifora [Willd.] Poir.): a review of its traditional use, phytochemistry and pharmacology. Brazilian Archives of Biology And Technology 51:937-947.

Yang, C., Hamel, C., Vujanovic, V., Gan, Y . 2011. Fungicide: Modes of Action and Possible Impact on Non target Microorganisms. International Scholarly Research Network 2011:1- 8.

Zhu, Y., Mao, Y., Chen, H., Lin, Y., Hu, Z., Wu, J., Xu, X., Xu, X., Qin, J., Xie, L. 2013. Apigenin promotes apoptosis, inhibits invasion and induces cell cycle arrest of T24 human bladder cancer. Cancer Cell International 54:1-7. 